\title{
Using emotional core therapy to effectively treat those individuals suffering from eating disorders.
}

\author{
Robert A Moylan* \\ LCPC (Licensed Clinical Professional Counselor), North-western University, Greater Chicago, USA.
}

\begin{abstract}
Emotional core therapy is scientifically proven to be the most effective behavioral psychology approach available worldwide to treat relationship stress such as eating disorders. For the first time in history, we have a behavioral psychology approach that treats the root cause of eating disorders and other relationship stress. Emotional Core Therapy (ECT) is the most effective psychology approach available worldwide to treat eating disorders. This includes eating disorders such as anorexia nervosa, bulimia nervosa, binge eating disorder, purging disorder, night eating syndrome, and pica. Key to this process is the aspect of learned behavior and the capacity to unlearn negative behaviors. Emotional Core Therapy (ECT) uses compassion and empathy while teaching one how to relearn positive eating habits. This often takes a great deal of time and often times regression and relapse occur as the ECT process often takes between 5-20 hours or more to learn and apply. ECT utilizes a team approach which seeks to empower clients through informed knowledge of environmental stressors. This includes the latest medication management as well as education on what food particles one is digesting. The ECT process also explains how the rules of scientific evidence are used to disseminate the truth behind behavioral psychology research and ECT.
\end{abstract}

Keywords: Emotional core therapy, Eating disorder, Cognitive psychology.

Accepted on October $29^{\text {th }}, 2018$

\section{Introduction}

It is important to allow each reader to view and learn the ECT process at their own pace. Having taught the ECT process for years, it is vitally important to give needed support to those trying to acquire knowledge on a complex group of issues. Acceptance to the varying learning styles as well as different aptitude levels is important. Some readers may only want to learn a few steps of the ECT process. Others may want to learn all eight steps over a span of several months. To each of them, the vast majority of resources to combat the problem of an eating disorder can be overwhelming. That is why it is important to tailor the eight step model to each individual.

Let us begin with a hypothetical client named Mary, who is suffering from anorexia nervosa. For Mary, let us assume she has an average intelligence and ample amount of time to learn and process the behavioral psychology approach called Emotional Core Therapy. She also has a psychiatrist she is working with for medication management. Ideally, we would want Mary to review and learn the eight step process at her own pace. This, as mentioned before is not an easy process. Over the years, clients typically taken between 5-20 hours or more to learn the basic eight step process. Once the reader learns the process, the next step is to apply ECT to their own lives. It is important to remember people spend a great amount of time learning religious, 12 step, or psychology approaches that only partially work to treat stress. Examples such as Christianity, Buddhism, Dialectical Behavioral Therapy, Cognitive Behavioral Therapy, are some of the hundreds of models available in the world today. This research shows that these approaches only have circumstantial evidence of effectiveness. The only model in existence with direct scientific proof of effectiveness is Emotional Core Therapy. In the case of Mary, she has read and learned the necessary steps to the eight step process. This includes the Emotional Core Manuscripts [1,2] and Emotional Core Training Video [3].

The Holmes and Rahe Scale highlight some of the most common stresses facing humans (Table 1). It is important at this point to ask a few questions. Why expand hours upon hours learning Emotional Core Therapy? What differentiates ECT from any of the hundreds of psychology or religious approaches currently available worldwide? The answer is quite simple. From the time we are born, till the time we die, human beings suffer stress. This stress can be very uncomfortable and debilitating for human beings. The only behavioral psychology approach available worldwide to identify and treat the root cause of psychological stress is Emotional Core Therapy. What is the root cause of psychological stress? The root cause of psychological stress is the temporary arousal of one of the four true emotions. These four emotions are joy, grief, fear, and relief. These emotions evolve from entering and leaving a relationship. Human beings encounter relationships throughout their lives. Therefore, it is essential, to learn to identify, treat and release these temporary emotions as quickly as possible. Emotional Core Therapy (ECT) is the only model in existence that effectively treats this situational stress each time it is used correctly. 
Citation: Moylan RA. Using emotional core therapy to effectively treat those individuals suffering from eating disorders. J Clin Psychiatry Cog Psychol. 2018;2(2):14-18

Table 1. The Holmes-Rahe Life Stress Inventory: The Social Readjustment Rating Scale

\begin{tabular}{|c|c|c|}
\hline & Life event & Mean value \\
\hline 1 & Death of spouse & 100 \\
\hline 2 & Divorce & 73 \\
\hline 3 & Marital Separation from mate & 65 \\
\hline 4 & Detention in jail or other institution & 63 \\
\hline 5 & Death of a close family member & 63 \\
\hline 6 & Major personal injury or illness & 53 \\
\hline 7 & Marriage & 50 \\
\hline 8 & Being fired at work & 47 \\
\hline 9 & Marital reconciliation with mate & 45 \\
\hline 10 & Retirement from work & 45 \\
\hline 11 & Major change in the health behaviour of a family member & 44 \\
\hline 12 & Pregnancy & 40 \\
\hline 13 & Sexual Difficulties & 39 \\
\hline 14 & Gaining a new family member (i.e. Birth, adoption. older adult moving in, etc.) & 39 \\
\hline 15 & Major business readjustment & 39 \\
\hline 16 & Major change in financial state (i.e... a lot worse or better off than usual) & 38 \\
\hline 17 & Death of a close friend & 37 \\
\hline 18 & Changing to a different line of work & 36 \\
\hline 19 & $\begin{array}{l}\text { Major change in the number or argumenta w/spouse (i.e.. either a lot more or a lot less than usual regarding child rearing, personal } \\
\text { habits, etc.) }\end{array}$ & 35 \\
\hline 20 & Taking on a mortgage (for home, business, etc.) & 31 \\
\hline 21 & Foreclosure on a mortgage or loan & 30 \\
\hline 22 & Major change in responsibilities at work (i.e. promotion, demotion, etc.) & 29 \\
\hline 23 & Son or daughter leaving home (marriage, attending college, joined mil.) & 29 \\
\hline 24 & In law troubles & 29 \\
\hline 25 & Outstanding personal achievement & 28 \\
\hline 26 & Spouse beginning or ceasing work outside the home & 26 \\
\hline 27 & Beginning or ceasing formal schooling & 26 \\
\hline 28 & Major change in living condition (new home, remodelling, deterioration of neighbourhood or home etc.) & 25 \\
\hline 29 & Revision of personal habits (dress manners, associations, quitting smoking) & 24 \\
\hline 30 & Troubles with the boss & 23 \\
\hline 31 & Major changes in working hours or conditions & 20 \\
\hline 32 & Changes in residence & 20 \\
\hline 33 & Changing to a new school & 20 \\
\hline 34 & Major change in usual type and/or amount of recreation & 19 \\
\hline 35 & Major change in church activity (i.e.. a lot more or less than usual) & 19 \\
\hline 36 & Major change in social activities (clubs, movies, visiting, etc.) & 18 \\
\hline 37 & Taking on a loan (car, TV, freezer, etc.) & 17 \\
\hline 38 & Major change in sleeping habits (a lot more or a lot less than usual) & 16 \\
\hline 39 & Major change in norm of family get-togethers ("'") & 15 \\
\hline 40 & Major change in eating habits (a lot more or less food intake, or very different meal hours or surroundings) & 15 \\
\hline 41 & Vacation & 13 \\
\hline 42 & Major holidays & 12 \\
\hline 43 & Minor violations of the law (traffic tickets, jaywalking, disturbing the peace, etc.) & 11 \\
\hline
\end{tabular}

Instruction: Mark down the point value of each of these life events that has happened to you during the previous year. Total these associated points.

Now, add up all the points you have to find your score.

150pts or less means a relatively low amount of life change and a low susceptibility to stress-induced health breakdown.

150 to 300pts implies about a $50 \%$ chance of a major health breakdown in the next 2 years.

300pts or more raises the odds to about $80 \%$, according to the Holmes-Rahe statistical prediction model.

As one can see, the crisis that Mary faces with her Anorexia Nervosa Disorder can actually be viewed as "great opportunity". What is the opportunity? The opportunity is to finally learn the simplest and most effective model that helps to navigate one's life to a state of peace and happiness. How does this happen? The four emotions serve as a navigation tool. As individuals embrace their four true emotions, they become more confident in their choices. They learn to navigate towards relationships that bring them joy and relief. And thus leave relationships that bring them grief and fear. All this comes from learning to monitor one's body for psychological stress. Also key is to empower each individual for their relationship choices.

Mary suffered some of the classic symptoms of an Anorexia Nervosa patient. She restricted her eating patterns to twice a day 
$v s$. three to four times a day. She had an intense fear of gaining weight and persistent behaviors to avoid gaining weight, despite being under weight. This included eating only small portions at dinner of main dishes such as pasta or chicken. Mary also had a relentless pursuit of thinness and unwillingness to maintain a healthy weight. This included exercising on a treadmill for several hours a day. This in turn affected her sleep patterns and made her chronically tired. Each patient like Mary has unique behaviors that adversely affect her health. The Emotional Core Therapy process is readily equipped to allow Mary to make an informed decision on each of her behaviors. Thus empowering Mary and helping her gain confidence. Let us now look at all three decisions faced by Mary utilizing the eight steps ECT flowchart (Figure 1). It will be helpful to have a copy of the eight step process nearby as we help Mary understand and apply ECT to her life.

Step 1- To examine each relationship one enters into. This includes relationships with people places and things. In this instance, Mary is choosing to eat smaller portions of her meals that can provide her with a healthy nutrition and caloric intake. Caloric intake is simply the number of calories an individual consumes on a daily basis. Calories are defined as the amount of energy contained in the food that an individual consumes. This is similar to fuel in a car. One needs gas to get a car moving along the highway. The same thing goes for food with humans. Humans need a basic level of food and calories to function. Mary was harming herself by restricting the amount of food she is eating during her mealtime. The analogy would be akin to stopping for a gasoline but only filling up a half tank when one needs a full tank to drive on a long trip. Eventually, one runs out of fuel. The first step becomes empowering for patients like Mary as they begin to see they have the power to choose the relationships they enter into.

Step 2- To examine the needs that cause one stress. In this case, Mary is choosing to have smaller portions of the food she is supposed to eat for a minimum healthy diet. Needs that cause one stress can be broken down into four categories. Emotional, financial, spiritual, and physical. In Mary's case, her decision to restrict her intake of food falls into the physical category. Mary's body is likely suffering stress because of lack of needed food which is a source of energy. Again, the second step is one of the key steps of the ECT process. Why? The everchanging needs of the world, necessitate having a behavioral model that can identify the varying needs that someone like Mary will encounter. A person, like Mary, will become vigilant at examining the environmental needs in her life. This is not as difficult process as it seems. Most people understand danger when they see it in front of them. For example, Mary will not be trying to play dodgeball on the expressway or walk outside on a wintery day in her bikini. Why? She knows that those behaviors will cause her undo stress, much like putting her hand on a hot stove. An empathetic and caring therapist can articulate how a certain level of food is necessary for basic functioning. Once one has a full understanding of ECT, they take responsibility for all their relationship choices, including eating and drinking.

Step 3- To examine which senses are affected by the external needs one faces in the environment. The five senses are seeing, touching, smelling, tasting, and hearing. This third step happens quite automatically for nearly all humans. For Mary, she was touching her food while she ate. So that sense was used. She was also looking at her food on the table, so her sense of sight was used also. She also was able to smell her food so that was another sense that was being used. Mary began to be in tune with her senses by using ECT. This allowed her to take more ownership of her body and mind.

Step 4- To examine which emotion was evoked by entering into a new relationship they have chosen. For Mary, she thought that skimming on her meals would bring her joy, but this was not the case. By shortchanging herself on her daily diet, Mary was experiencing feelings of grief. By getting in touch with her authentic emotion of grief, Mary is finally taking a road back to health. She can decide to have less grief in her life by eating full portions at her daily meals. As one can see, each crisis becomes an opportunity for growth. The key is to be compassionate and understanding as one learns the basic four emotions. As we discussed early with Mary, she is making other poor decisions regarding her health. Such as skipping meals, excessive exercise, and lacking enough sleep. For each of these relationship choices, Mary can utilize the eight step process. One may ask, why not force all patients to learn ECT prior to beginning therapy? That would be intrusive and inappropriate. Psychology professionals take an oath to "Do No Harm". This means that they cannot use techniques to cause patients to suffer. Forcing therapy techniques upon a patient can cause undue stress. For each

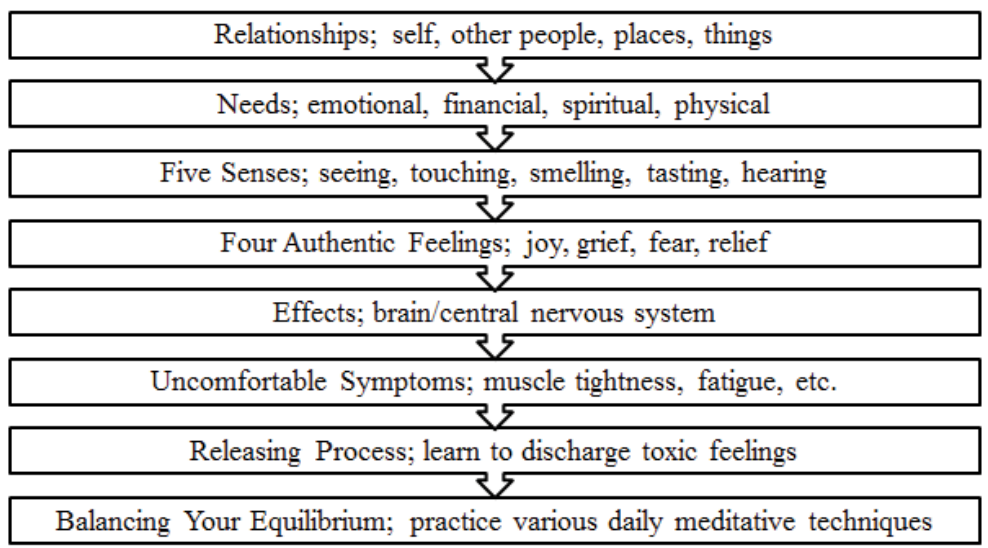

Figure 1. This depicts the natural state of psychological stress. Aspects of these eight steps happen in every stressful event. 
behavioral psychology technique used to unlock stress, it is important to fully inform clients prior to the using the technique. An example would be using Hypnosis or EMDR. These techniques may or may not work to cathartically release stress. Another example would be a doctor prescribing medications to someone like Mary suffering from an eating disorder. It is important to fully inform clients of all the risks associated with the medications prescribed. Behavioral psychology, like medication management, is a trial and error process. The key is to get ongoing feedback from patients like Mary to see how they are truly feeling. Also, to see if they are truly progressing. Sometimes patients have distorted images of themselves. The more acute patients need extra support sometimes, like inpatient hospitalization or partial hospitalization.

Full acceptance of a patient is necessary for trust to be built up. This trust is necessary for patients to fully disclose how they feel. Some patients may only want to learn a few of the steps of ECT. Others may not want to learn more than one step. Patients vary in educational and aptitude levels. The therapist has to embrace each patient and accept them wherever they are in life. That being said, mastering one's emotions is an arduous task. The dilemma clients endure is that the emotions one face in life are clear and present. Would you rather run away continuously? Therefore making the same mistakes over and over? Or would you rather learn and embrace each moment? A practical example would be a little boy touching a hot stove. The emotions this boy feels is grief. Why not embrace this event and have learned that grief is a toxic emotion that can cause the body harm, if experienced long term.

Step 5- To have the emotions register with the brain and central nervous system. This is an automatic step for Mary and nearly all humans. It helps people to understand the cause and effect relationship with stress. The brain notifies certain body parts of stress on the nervous system. Again, the emphasis on toxic emotions needs to be made. The sooner in life one learns that having excess fear and grief in your body and mind is harmful, the better.

Step 6- To experience the bodily stress. Each person likely experiences bodily stress differently. Some may have pain in their chest, while others suffer headaches. Often times patients like Mary suffer immensely as their body is suffering malnutrition. This causes patients like Mary grief and physical pain. This in turn causes more suffering. A cycle of trauma on the body ensues. Mary was feeling her stress predominantly in her stomach and lower back. I often have clients like Mary rate themselves from $1-10$ with 10 being the most severe. Healthy people with normal eating habits likely have a 1-2 rating throughout the day. In the case of Mary, suppose she rates herself as an 8 on a scale of 1-10. This is her perception. The goal of therapy would be to have her back to a 1-2 when therapy concludes. Every patient varies in their recovery outcomes. That is why it is essential to treat therapy as a supportive process to recovery.

Acceptance of clients is paramount to treatment and recovery. Sometimes patients like Mary regress. Therapy is not a linear process. The more we can have patients like Mary learn to rate themselves with their emotions, the more likely treatment will improve and move in a positive direction. Why? The patient is learning to feel empowered by having some control over their treatment. One can begin to see how easy it is to transfer the ECT process to other stress that Mary may face during treatment. What if she is prescribed medications for her erratic sleep patterns and chronic fatigue. Step by step, we examine and rate Mary on her perception of how she feels. By transitioning the ECT process to all of the factors causing Mary stress some positive outcomes may occur. Mary will become more confident in the ECT process to combat her illness. She will realize the temporary state of stress. Learning to resolve emotional duress can often help patients to feel empowered by their treatment and more in control of their lives.

Bodily stress for eating disorder patients can take many forms. An example would be someone suffering from obesity. The same can be said for obese individuals as with other treatable eating disorders. The excess weight they carry on their body likely causes them grief. Each day they are reminded of the grief throughout the day, thus causing cyclical grief. Unless treated, the obese client may suffer a dual diagnosis often of obesity and grief. Grief is otherwise known as depression, when experienced it is experienced long term. Whatever the type of eating disorder, it is important to take notice of the emotional component as that is where some of the most insightful learning can take place. People are more motivated to change when things make them sad, versus happy. That is why crisis's can indeed be learning opportunities.

Step 7- It is the releasing process. Learning to cathartically release the emotions that cause one stress. Any psychology technique that has demonstrated effectiveness at releasing stress can be utilized. Verbalization of emotional duress is one of the most popular therapy techniques. Otherwise known as talking therapy is the most common way to release emotions. An empathy based approach, like Emotional Core Therapy focuses on having a receptive milieu to cathartically release emotions like grief and fear. Some other common ways to release emotions are Role Playing, Gestalt Therapy, Music Therapy, Art Therapy, Prayer, etc. Both the attached manuscript and video offer ways to release emotions. The focus of ECT is to externalize stress. In Mary's case, she worked with a behavioral therapist who, using the ECT process was very in tune with Mary's sadness/ grief. Once Mary realized the harmful impact of her behavior of skimming on meals, she began to verbalize her pain. By giving a voice to this pain, and taking ownership of this grief, Mary was able to take steps to ameliorate her condition.

Step 8- To regain one's equilibrium. Every stressful event in one's life can be viewed as a "cause and effect" situation. That means there exists a beginning and end. For all intensive purposes, there really only needs to be seven steps for the ECT process to be successful. Why? Once a patient releases stress, the activity is over and they begin to take on new stress. ECT builds off the work of other successful psychology and religious approaches where a "reset button" occurs. The rest button is the state of returning to a balanced equilibrium. Since nearly 
all psychic pain dissipates over time, it becomes very helpful to learn how to reset one's emotions. During the last 10-20 years lots of research has focused on ways to reset and relax. Prayer and mindfulness are two of the better researched topics.

In the case of Mary, she focused on deep breathing exercises and staying in the here and now. By calmly paying attention to her body taking slow and deep breaths, Mary felt more relaxed and reflective. These were small aspects of her mindfulness training she learned with her therapist. As we finish our case study of the hypothetical case of Mary, it is helpful again to remind the reader that ECT effectively identifies and treats situational stress. Nearly all situational stress human beings like Mary encounter can be identified and processed effectively through the ECT flowchart. Why can no other behavioral psychology or religious approach boast this claim? Aspects of the eight steps happen in any stressful event one encounters [4]. This occurrence happens whether you like it or not. Therefore, a full understanding of ECT allows one exceptional confidence that they can overcome some of the traumatic and debilitating events in one's life. Behavioral psychology has some limitations that are outlined [5].

The ECT process works just like entering data in a computer [6]. Just input your situational stress into the ECT process and the product can be a peaceful state of being. It is that exacting, if used properly and correctly. The easiest way to test the process is to reflect on past stressful events. In regards to the topic of eating disorders, there are hundreds, if not thousands, of external stressors effecting patients like Mary. This includes variations of dietary intake when one examines each food product for example, drinking excess amounts of soda pop. There are small cans of soda. There are soda bottles. One can even drink soda out of a tap at a bar or saloon. In addition, there is diet soda, and other variations to the regular soda pop such as Jolt, which has excessive caffeine amounts. My point is that there exist many stressors [7].

\section{Conclusion}

Although many people have utilized parts or all of the ECT process successfully to identify and treat stress, these results only provide circumstantial proof of effectiveness. For direct scientific proof, one needs to utilize the eight step process oneself. Scientific evidence can be done with the naked eye. In the case of psychology approaches, this is the most optimum way of demonstrating effectiveness. Since each individual perceives eating disorders stress differently, results will vary from person to person. While learning the ECT process, there can be regression and relapse. The only way to minimize relapse is to be fully aware of your surroundings and your emotional response to the environment.

\section{References}

1. Moylan RA. Emotional Core Therapy. IJMSCI. 2016:3(2).

2. http://emotionalcoretherapy.com/_

3. https://www.youtube.com/watch?v=ty9OE2lqNX8

4. Moylan RA. Using emotional core therapy to effectively treat those individuals suffering debilitating physical injuries requiring rehabilitation. Int Phys Med Rehab J. 2018:3(4);304-7.

5. Holmes TH and Rahe RH. The Social Readjustment Rating Scale. J Psychosom Res. 1967:11(2);213-8.

6. Moylan RA. Using prayer and spirituality in the healing professions with emotional core therapy. Curr Med Res Opin. 2018:1(5);23-28.

7. Moylan RA. Learn to Effectively Minimize Regression and Relapse in Patients with Emotional Core Therapy. ASMS. 2018:2(7);103-108.

\section{*Correspondence to:}

Robert A Moylan

LCPC (Licensed Clinical Professional Counselor), North-western University, Greater Chicago, USA. 